\title{
Discussion of Kelley's Article
}

\author{
Alvin Zander \\ University of Michigan
}

The ideas offered by Harold Kelley are rich and stimulating. They provide an explanation of complex interpersonal events based on simple and sensible assumptions. He shows new ways of thinking about matters we thought were well settled and ingenious means for deriving unfamiliar leads out of familiar approaches. Best of all, he suggests why and how persons make changes in their established relations with other individuals - a topic that has been too long ignored.

More than in most scientific disciplines, social psychologists pay much attention to how one should go about building a theory. Those of us (of which Kelley was one) in the Research Center for Group Dynamics (RCGD) in its early days were especially interested in how to make theory because we had no supply of research findings in group life; there was little evidence that we could borrow from social psychology; we had a powerful set of intellectual tools in the concepts Kurt Lewin had provided; we had seen Lewin's ideas and methods work well in opening up research on other topics; we had seen physicists and chemists select events for study that allowed them to exploit the logic of mathematics; we saw no reason why we could not build a special mathematics (perhaps a nonquantitative one) that would similarly help students of groups; and we had Dorwin Cartwright and Frank Harary to help us in this task. As we know, considerable progress was made in developing a mathematics for group dynamics, but the task turned out to be much larger than any of us had thought it would be. The interest in how to theorize effectively about group behavior is not quite as lively in the center today, and the study of groups often appears to be a flickering flame tended most carefully by Eugene Burnstein. Yet, of 24 different theories I can recall being developed in the RCGD in its whole history, I believe that only six have no relevance at all to the social psychology of group life. Our local group of groupies has been more groupey than some groups think.

Kelley had his plate more than full today in what he attempted to do for us. I hope, however, that someday he will present in more detail ways that these ideas might be useful in explaining relations among more than a pair of persons. Interpersonal relations means more than dyadic interactions and more than the making of decisions about how individuals might act toward one another. Kelley's use of a matrix in developing a model of relations within a twosome is helpful, but the matrix causes him to ignore matters beyond the interaction within that duo. A matrix is a simple, neat, even elegant device; yet it forces the user to set aside a large share of empirical reality that ought somehow to be considered when explaining connections among individuals outside a laboratory. 
The use of a matrix furthermore requires the scholar to think in terms of only two individuals, each of whom is merely a stimulus for the partner-each a source, for instance, of rivalry or of help. It inspires theoretical thinking in polar terms, one on one. Thus, the four properties of a matrix proposed by Kelley and Thibaut describe how each individual depends on the other individual and what each decides to do in that relationship.

Suppose that we now recognize that a third psychologically significant entity is potentially present in the situation described by Kelley. This third entity is the pair itself: a partnership-due perhaps to marriage, business, or tennis - that is greater (at least some of the time) than the sum of its parts. Such a unit, like each of its members, can have a name, rights, a reputation to protect, a task to accomplish, and private property; and it can demand that consideration be given to what is best for the pair as a unit, not only for each individual who happens to be in the presence of the other. In such a case, the properties of the relationship describe not only (a) what each person prefers for himself (Kelley calls this a given), but also (b) what each person prefers for the good of the pair treated as one, as well as (c) the pair's jointly decided agreement on what they both prefer for the pair, and (d) the pair's jointly decided preference for what each person should do for his or her own good. The preferences of two persons acting for the good of their unit, I submit, are not the same as the preferences Kelley says each person develops once that individual transforms his or her needs by taking into consideration what the partner wants.

We can better understand my assumption about the pair being treated as a unit if we take it for granted that both partners are members of a larger group that included their duo, and that they must help make a decision for that larger body. In such a case, we readily see that the members may ignore their own preferences in order to choose that which their group needs. This kind of group-centered behavior happens every day to every good member and administrator. But few psychologists pay attention to it as an aspect of interpersonal life. Many social psychologists, moreover, deliberately choose to be biased in their choice of topics for study, holding - in accord with the basic values of democratic societies-that both individuals and institutions exist only for individuals, but individuals never exist for their institutions. Because of this bias, they study individuals in group settings but do not study the groups as wholes.

A dampened enthusiasm for trying to understand the psychology of groups is not surprising when we recall that making strong theories about events in groups is difficult to do. We have never figured out, for instance, how to combine properties or subjective experiences of persons so that they are qualities of their group as a unit, rather than a description of the average member. Saying it differently, we do not know how to combine the lifespaces of individual members into one lifespace for the group. Making theories about group behavior is cumbersome, moreover, when the surroundings of a group contain a stimulus that reaches all members. In such a case we are not sure on 
whose behalf members are responding-for themselves, for colleagues, or for the group as a unit. Likewise, we have trouble in conceiving of a group as an acting entity: How are stimuli sensed in a group, acted upon, or ignored? Then too, studying groups is more inconvenient than studying individuals. It requires too many subjects, conditions are harder to control during an experiment, reliable measures are harder to obtain, analyses of the data are more complicated, and the phenomena in natural settings are too elusive to examine closely.

Unaccountably, the results of some investigations win more followers than do the findings of others. All of us know, as well, of excellent theories that have gone unnoticed by colleagues. I believe that Kelley's propositions today will inspire theory and research among his colleagues, because his proposals can be used in approaching many matters in interpersonal relations. But an explanation of events needs more than substantive value if it is to be welcomed by scholars. It must also have properties which, according to Cartwright, characterize research topics that become popular among psychologists. Kelley's approach includes most of these qualities.

(1) The basic assumptions must be few, simple, and clear.

(2) Hypotheses must be easy to derive.

(3) A number of these hypotheses must present interesting paradoxes by being tangential to common sense or to previous findings in research.

(4) There must be a quick and easy research method for use in testing these hypotheses.

(5) The theory must have a notable label. (Here I suggest the following labels: the happy shift, the transformed duo, the one-on-one conversion, the double -jointed compromise, or transformation as consummation.)

(6) Parts of the theory must be open to contrasting interpretations so that disagreements can develop among interested scholars.

(7) The initial statement must be made by a well-known and respected scientist at an important university.

In the light of the favorable comments that John French and I have made about Kelley's statement, I expect that his ideas will be an important guide for his future research. Fortunately, Kelley in Los Angeles has Dorwin Cartwright nearby in Santa Barbara, so he can benefit from Cartwright's questioning and suggesting when Kelley is testing the approach he has suggested in this issue.

Alvin Zander was Director of the Research Center for Group Dynamics and Professor of Psychology at the University of Michigan for twenty years. He is now a program director at the center. His newest book, published in 1982, is entitled Making Groups Effective. 